\title{
A comparison of the fat composition and prices of margarines between 2002 and 2006, when new Canadian labelling regulations came into effect
}

\author{
Laurie Ricciuto, Kevin Lin and Valerie Tarasuk* \\ Department of Nutritional Sciences, University of Toronto, 150 College Street, Toronto, Ontario, Canada, M5S 3E2
}

Submitted 29 January 2008: Accepted 15 September 2008: First published online 6 November 2008

\begin{abstract}
Objective: To examine the effect of the new Canadian labelling regulations on the fat composition and prices of margarines.

Study design: A survey of all margarines sold in major supermarkets in the Greater Toronto area was conducted in 2006, and results were compared with those of a similar survey conducted in 2002. Average fat composition, proportion of 'trans fat-free' margarines and average prices of margarines were compared. A general linear model procedure was used to compare the relationship between price and fat composition in 2002 and 2006.

Results: Average amounts of trans fatty acids (TFA) and MUFA decreased, while average amounts of PUFA increased significantly from 2002 to 2006. The proportion of margarines with less than $0 \cdot 2 \mathrm{~g}$ TFA $/ 10 \mathrm{~g}$ serving rose significantly from $31 \%$ in 2002 to $69 \%$ in 2006. Margarines lower in TFA on average cost significantly more than margarines with greater amounts of these fats, and this relationship appeared stronger in 2006 relative to 2002.

Conclusions: There is evidence of reductions in TFA in margarines since new labelling regulations came into effect in Canada; however, TFA reductions appeared to be restricted to higher-priced margarines. Results suggest that voluntary approaches (i.e. manufacturer incentives via labelling) to reduce population intakes of TFA will yield little changes in TFA content of low-cost products and thus may have limited benefit for lower-income groups, who are at higher risk of heart disease.
\end{abstract}

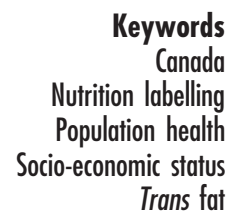

Trans fat
Nutrition labelling of pre-packaged foods is increasingly promoted as an important public health strategy for altering population diets, with the ultimate goal of reducing the prevalence of diet-related diseases ${ }^{(1-6)}$. While the specific details vary across jurisdictions, nutrition labels generally include nutrient content information, typically displayed in a standardized format, and nutrition claims based on either nutrient content (e.g. 'low-fat') or dietdisease links (e.g. 'A healthy diet low in saturated and trans fats may reduce the risk of heart disease'). Nutrition labelling is thought to effect change in population diets via its impact on consumer food choices, food production and product marketing ${ }^{(7)}$. There has been considerable study of the impact of nutrition labelling regulations on consumer behaviour ${ }^{(3,8-10)}$, but less research on labelling regulations in relation to food production and marketing.

Nutrition labelling can alter food production by serving as a stimulus for improvements to the nutritional quality of foods being sold ${ }^{(11-13)}$. In the mid-1980s, a period when fibre-related health claims proliferated in the USA, the fibre content of ready-to-eat cereals sold improved ${ }^{(12)}$.
Study authors attributed the improvement to competitive pressures on manufacturers to market their products on the basis of their nutritional benefits. Similarly, improvements in the nutritional quality of over 100 foods from twenty-one food categories occurred following the implementation of labelling regulations in the USA in the early $1990 \mathrm{~s}^{(13)}$, which required nutrient content disclosure on most pre-packaged foods.

Nutrition labelling can also influence how manufacturers market their products. The same study that demonstrated nutritional improvements in many foods following nutrition labelling regulations in the USA also indicated a shift in price promotion levels depending on the 'health positioning' of the products ${ }^{(13)}$. Foods positioned as 'healthy' (i.e. using nutrition claims to promote their nutritional benefits) were marketed at relatively higher prices while other foods, not touting such benefits, were promoted on the basis of their lower price. This pricing activity is consistent with other research indicating that nutritionally improved foods tend to cost more than their regular counterparts ${ }^{(14,15)}$. In this regard, labelling 
may have differential impacts on consumers, raising questions about its effectiveness as a population health strategy.

Recognition of the detrimental effects of trans fatty acids (TFA) on cardiovascular health ${ }^{(16-19)}$ has prompted governments and health organizations in several countries to explore population strategies to reduce TFA intakes $^{(20-22)}$. While some jurisdictions in Canada and the USA have banned the use of trans fat in restaurants locally, at the national level nutrition labelling is being used to promote reductions in TFA intake. In 2002, new food labelling regulations in Canada required most prepackaged foods to disclose trans fat content and allowed qualifying foods to display 'trans fat-free' claims ${ }^{(23,24)}$; shortly thereafter, similar legislation was passed in the $\mathrm{USA}^{(25)}$. The required disclosure of trans fat content and greater opportunity to promote foods based on their lack of trans fat can provide incentives to manufacturers to voluntarily reduce or eliminate TFA in their products. However, TFA labelling is a relatively new phenomenon; the degree to which products will be reformulated to reduce TFA and how prices will be affected as a result of labelling regulations are unknown.

In the present study, we examine the effect of the new Canadian labelling regulations on the fat composition and prices of margarines. Our objectives were to compare the fat composition and average price of margarines (a significant source of TFA in the North American diet ${ }^{(26,27)}$ ) sold in 2002 with those on the market in 2006 (when all products were required to comply with new labelling regulations), and to compare relationships between price and fat composition for 2002 and 2006.

\section{Methods}

\section{Margarine survey}

A survey of margarines sold in major supermarkets in the Greater Toronto area was conducted in November $2002^{(28)}$ and repeated in November and December 2006. In each year, supermarkets were selected based on their market share in Ontario and their presence in the Greater Toronto area. Three major chain supermarkets together accounted for $75 \%$ of grocery sales in Ontario in $2002^{(29)}$ and $63 \%$ in 2004 (the most recent year for which data were available) ${ }^{(30)}$. Each chain operates a variety of stores under different names ('banners') (31) and pricing is consistent across all branches of a banner located in the same geographic region. The survey was conducted in one branch of each banner of these chains, resulting in data collection from nine supermarkets in 2002 and ten in 2006.

In each supermarket, the brand, package size, regular price and fat composition of all margarines sold were recorded, excluding lower-fat and organic products. This yielded data on 229 margarines, representing thirtyfour different brands, in 2002, and 274 margarines, representing thirty-six different brands, in 2006. Manufacturers were required to declare the amount of TFA on the label in 2006 but not in 2002. Labelled amounts of TFA are determined according to the Association of Analytical Chemists' Method $9906.06^{(32)}$. For 2002, the TFA amounts were calculated by subtracting the amounts of the labelled fat components (SFA, PUFA and MUFA) from the total fat amount. In 2006, we found forty-one margarines without PUFA and MUFA amounts on the label (displaying these amounts on the nutrition label is optional ${ }^{(24)}$ ). This information was obtained from the manufacturers for nine products; the remaining thirty-two were omitted from analyses requiring data on individual PUFA and MUFA amounts.

\section{Statistical analysis}

To test whether the average fat composition of margarines had changed between 2002 and 2006, the amounts of SFA, TFA, PUFA and MUFA per serving were compared using a Wilcoxon sign-rank test. This non-parametric test was used because the distribution of data for each of the fatty acids was non-normal and could not be transformed to achieve normality. A $\chi^{2}$ analysis was used to compare the proportion of 'trans fat-free' margarines sold in 2006 with those sold in 2002. A margarine was considered 'trans fat-free' if it contained $\leq 0 \cdot 2 \mathrm{~g}$ TFA and $\leq 2 \mathrm{~g}$ TFA and SFA combined, per $10 \mathrm{~g}$ serving, and $\leq 15 \%$ energy from TFA and SFA combined per serving, the limits prescribed for a product to qualify for the 'trans fat-free' claim $^{(23)}$. For each survey year, the prices of margarines meeting these criteria were compared with the prices of others sold, using a two-tailed $t$ test.

The data from the two survey years were pooled and a general linear model procedure applied to compare the relationship between price and fat composition in 2002 and 2006. Price per kilogram was the dependent variable and the independent variables were fat amount, year and an interaction term, fat amount $\times$ year.

To examine changes in margarines between 2002 and 2006, we identified products that had been on the market in both years and compared their fat composition and mean price at the two time periods. A two-tailed $t$ test was used to compare percentage change in price with the presence of a 'trans fat-free' claim. The margarines included in these analyses were those with the same brand name in 2002 and 2006 (eighteen products, accounting for 154 of the 229 margarines surveyed in 2002 and 188 of the 274 surveyed in 2006). Any margarines that underwent a name change between 2002 and 2006 were not be captured in these analyses, so there is a potential for bias; however, the margarines included accounted for more than half the sample in both 2002 and 2006.

All statistical analyses were performed using the SAS/ PC statistical software package version 9·1 (SAS Institute, Cary, NC, USA). 


\section{Results}

From 2002 to 2006, the average amounts of TFA and MUFA in margarines decreased, while PUFA increased and SFA did not change significantly (Table 1 ). The proportion of margarines with $\leq 0.2 \mathrm{~g}$ TFA $/ 10 \mathrm{~g}$ serving rose significantly from $31 \%$ in 2002 to $69 \%$ in 2006 $\left(\chi^{2}=70 \cdot 41, P<0 \cdot 0001\right)$. The proportion that qualified as 'trans fat-free' rose from $28 \%$ to $43 \%\left(\chi^{2}=13 \cdot 10\right.$, $P=0.0003)$ and $94 \%$ of those that qualified bore this claim in 2006. In both years, 'trans fat-free' margarines were significantly more expensive than others (Table 2).

In 2002 and 2006, margarines lower in SFA and TFA on average cost significantly more than margarines with greater amounts of these fats, while margarines higher in MUFA cost significantly more than margarines with lower amounts of these fats (Table 3). The relationship between price and TFA amount was stronger in 2006 compared with 2002, while the relationships between price, SFA and MUFA amounts were weaker in 2006 relative to 2002 (Table 3). In 2002, a decrease of $1 \mathrm{~g}$ TFA/10 g serving was associated with an average price increase of $\mathrm{C} \$ 1 \cdot 00 / \mathrm{kg}$, while the same decrease in TFA in 2006 was associated with an average price increase of $\mathrm{C} \$ 2 \cdot 00 / \mathrm{kg}$.

The TFA content of thirteen of the eighteen margarines identified as being on the market in both 2002 and 2006

Table 1 Comparison of average fat composition of margarines sold in 2002 and 2006, Greater Toronto area, Ontario, Canada

\begin{tabular}{lcccccr}
\hline & \multicolumn{3}{c}{ Fatty acid amount $(\mathrm{g} / 10 \mathrm{~g}$ serving $)$} \\
\cline { 2 - 3 } & \multicolumn{2}{c}{$2006(n$ 274 $)$} & & \multicolumn{2}{c}{$2002(n$ 229) } \\
\cline { 2 - 3 } Fatty acid type & Mean & SD & & Mean & SD & \multicolumn{1}{c}{$P^{*}$} \\
\hline SFA & 1.41 & 0.41 & & 1.29 & 0.18 & 0.7669 \\
TFA & 0.34 & 0.45 & & 0.80 & 0.66 & $<0.0001$ \\
PUFAt & 2.77 & 0.65 & & 2.42 & 0.76 & $<0.0001$ \\
MUFAt & 3.02 & 1.28 & & 3.39 & 0.83 & 0.0126 \\
\hline
\end{tabular}

TFA, trans fatty acids.

*Based on Wilcoxon sign-rank test.

$t n$ 242; missing data on thirty-two margarines.

Table 2 Comparison of average price per kilogram of 'trans fatfree' margarines* with others, by survey year, Greater Toronto area, Ontario, Canada

\begin{tabular}{|c|c|c|c|c|}
\hline & \multicolumn{4}{|c|}{ Mean price $(\mathrm{C} \$ / \mathrm{kg})$} \\
\hline & \multicolumn{2}{|c|}{2006} & \multicolumn{2}{|c|}{2002} \\
\hline & Mean & SD & Mean & SD \\
\hline Trans fat-free* & $\begin{array}{l}5 \cdot 10 t \\
(n 118)\end{array}$ & 0.94 & $\begin{array}{l}4 \cdot 62 \ddagger \\
(n 63)\end{array}$ & 0.44 \\
\hline Not trans fat-free & $\begin{array}{l}3.55 \\
(n 156)\end{array}$ & $1 \cdot 33$ & $\begin{array}{l}3.05 \\
(n 166)\end{array}$ & $1 \cdot 02$ \\
\hline
\end{tabular}

*Products containing $\leq 0.2 \mathrm{~g}$ trans fatty acids (TFA) and $\leq 2 \mathrm{~g}$ of TFA and SFA combined, per $10 \mathrm{~g}$ serving, and $\leq 15 \%$ energy from TFA and SFA combined per serving.

tColumn means differ significantly: $t=-11 \cdot 27$, df $=271, P<0.0001$.

$\ddagger$ Column means differ significantly: $t=-18 \cdot 84, \mathrm{df}=227, P<0.0001$. decreased over this period, in amounts ranging from $0 \cdot 1$ to $1 \cdot 3 \mathrm{~g} / 10 \mathrm{~g}$ serving (Table 4 ). The SFA content of six of these margarines rose concomitantly, and in three products, the increase in SFA equalled or exceeded the decrease in TFA content. The TFA content of three products increased between 2002 and 2006, and two others showed no change.

Of the eighteen products for which we had comparable data in 2002 and 2006, five qualified to make a 'trans fat-free' claim and four included that claim in 2006. The mean prices of these four margarines had increased, on average, by $28 \%$ (sD $8 \%$ ), whereas the average increase in price for the other margarines was only 10\% (SD 15\%). The difference in this change was statistically significant $(t=-2 \cdot 37, \mathrm{df}=16, P=0 \cdot 0307)$.

\section{Discussion}

The present study provides evidence of changes in margarine formulations since the new Canadian labelling regulations came into effect. Between 2002 and 2006, average amounts of TFA fell and the selection of 'trans fat-free' margarines on store shelves more than doubled. While these changes may in part be due to heightened demand for TFA-free products, manufacturer incentives, via labelling, likely also had an impact on margarine formulations. Consistent with earlier research in the $\mathrm{USA}^{(13)}$, our results indicate that the introduction of TFA labelling was not followed by improvements to the fat composition of all products; 'trans fat-free' margarines tended to be higher in price and the inverse relationship between TFA and price appeared stronger following implementation of the regulations.

It should be noted that because of the changes in labelling practices, there is some error in our comparison of TFA amounts across survey years. For 2002, the TFA amounts were calculated by subtraction whereas in 2006 these values were reported on the label. We have likely underestimated the true TFA amounts in 2002 by failing to

Table 3 Changes in the relationships between mean price per kilogram and fatty acid amount in margarines between 2002 and 2006, using pooled data set ( $n$ 503), Greater Toronto area, Ontario, Canada

\begin{tabular}{lrrr}
\hline & \multicolumn{3}{c}{$\beta^{*}$} \\
\cline { 2 - 3 } Fatty acid type & 2002 & 2006 & \multicolumn{1}{c}{$P+$} \\
\hline SFA & -2.09 & -0.98 & 0.0225 \\
TFA & -1.06 & -2.00 & $<0.0001$ \\
PUFA $\ddagger$ & 0.05 & -0.10 & 0.3853 \\
MUFA & 0.64 & 0.38 & 0.0156
\end{tabular}

TFA, trans fatty acids.

*Derived from the general linear model procedure: price per kilogram $=$ $\beta$ (fatty acid amount) + year + fatty acid amount $\times$ year. $\beta$ represents the change in mean price per kilogram with a change in fatty acid amount for a particular survey year. All $\beta$ values were significantly different from zero, except that for PUFA.

tFor the difference in $\beta$ between survey years.

$\ddagger n$ 242; missing data on thirty-two margarines. 
Table 4 Changes in the fat composition and price of eighteen individual margarine products between 2002 and 2006 , Greater Toronto area, Ontario, Canada

\begin{tabular}{|c|c|c|c|c|}
\hline $\begin{array}{l}\text { Change in TFA amount } \\
\text { (g/10 g serving) }\end{array}$ & $\begin{array}{c}\text { Change in SFA amount } \\
\text { (g/10 g serving) }\end{array}$ & $\begin{array}{l}\text { Change in MUFA + PUFA } \\
\text { amount }^{*}(\mathrm{~g} / 10 \mathrm{~g} \text { serving) }\end{array}$ & $\begin{array}{l}\text { Change in } \\
\text { price (\%) }\end{array}$ & $\begin{array}{l}\text { 'Trans fat-free' claim } \\
\text { on product? }\end{array}$ \\
\hline-0.1 & -0.1 & 0.3 & 20 & Yes \\
\hline-0.2 & -0.1 & 0.3 & 29 & Yes \\
\hline$-1 \cdot 3$ & -0.1 & 0.9 & 38 & Yes \\
\hline-0.1 & -0.2 & -0.1 & 25 & Yes \\
\hline-0.6 & -0.5 & $1 \cdot 1$ & 9 & No \\
\hline 0 & 0.5 & -0.7 & 20 & No \\
\hline-0.6 & $0 \cdot 8$ & $-1 \cdot 1$ & 19 & No \\
\hline-0.6 & $0 \cdot 8$ & $-1 \cdot 2$ & 16 & No \\
\hline-0.4 & 0.4 & $-0 . \overline{7}$ & 7 & No \\
\hline-0.4 & 0.2 & -0.3 & -10 & No \\
\hline 0.3 & -0.1 & -0.2 & 24 & No \\
\hline $0 \cdot 1$ & 0.1 & -0.8 & 4 & No \\
\hline-0.2 & -0.1 & -0.3 & 13 & No \\
\hline-0.2 & -0.1 & -0.3 & 23 & No \\
\hline$-0 . \overline{8}$ & 0.1 & 0.1 & 15 & No \\
\hline-0.4 & 0.2 & 0.2 & 17 & No \\
\hline 0.4 & 0.4 & -0.9 & -31 & No \\
\hline 0 & 0.2 & $-1 \cdot 2$ & 10 & No \\
\hline
\end{tabular}

TFA, trans fatty acids.

*When individual MUFA and PUFA amounts were unavailable, combined MUFA + PUFA amounts were obtained by subtracting the sum of SFA + TFA from the total fat amount.

take into account TFA in the PUFA and MUFA fractions. This in turn implies that we have underestimated the decreases in TFA occurring between 2002 and 2006. Therefore, our estimates of compositional changes are conservative.

While there were a greater number of 'healthier' margarines on store shelves following the introduction of TFA labelling, almost one-third of the margarines surveyed still had too much SFA and/or TFA to be considered 'low in saturated fat' or 'trans fat-free' according to Canadian labelling regulations ${ }^{(33)}$. This is consistent with the experience in Denmark. Prior to the government ban on processed trans fats in 2004, margarine producers voluntarily reduced TFA amounts in their products, in response to concerns about their harmful effects, but there still remained a significant number of margarines with relatively high amounts of $\mathrm{TFA}^{(19)}$. Only after a mandatory limit on TFA content was imposed were TFA virtually eliminated from the food supply ${ }^{(22)}$.

The fact that 'trans fat-free' margarines tended to be higher in price suggests that product reformulations were restricted to higher-end, higher-priced products or that manufacturers seized the opportunity provided by the labelling regulations to develop higher-end products. This finding is consistent with US and Australian research showing that reformulated products (e.g. lower fat, lower salt, reduced sugar) tend to be higher in price ${ }^{(13,15)}$. In addition, the stronger price-TFA relationship and weaker price-SFA relationship following implementation of the labelling regulations suggests that TFA content became the primary point of differentiation between margarines. While higher ingredient costs for TFA substitutes relative to SFA substitutes likely contribute to the stronger TFAprice relationship, it is also possible that the 'trans fat-free' attribute became a more potent marketing tool over the survey years, allowing manufacturers to charge a price premium for margarines with this attribute.

The higher prices of 'trans fat-free' products imply that the health benefits of these products may not be felt among more price-conscious consumers and their families. These results are of concern for individuals in low-income households who tend to be at higher risk of heart disease ${ }^{(34)}$ and who often base their food choices on price ${ }^{(35-37)}$ and purchase more economical brands of certain foods ${ }^{(38)}$. Thus the association between nutrition labelling and price constitutes a major limitation of this as a strategy for population health. It could be argued that the imposition of mandatory regulations on TFA content would also result in increased prices because the additional cost of product reformulation to remove trans fats would be transferred to the consumer. However, this has not been borne out in Denmark where the TFA ban had no noticeable effect on the availability or price of foods previously containing high amounts of TFA ${ }^{(22)}$.

Our study is limited insofar as we are unable to differentiate the required disclosure of fat composition on all product labels from the impact of nutrient content claims and health claims (i.e. optional marketing tools). As well, our surveys were completed using a sample of supermarkets in only one city in Canada. It must be noted, however, that we would likely observe similar relationships elsewhere because many of the margarine brands found in Toronto are available nationally and relative prices would be unlikely to deviate by large amounts based on location. More importantly, our study is limited because we examined only one product, margarines, and we considered labelling regulations only in relation to product formulation. A much broader investigation is 
needed to determine the effects of nutrition labelling regulations on other foods and on food consumption patterns across the population.

In conclusion, there is evidence of reductions in TFA in margarines since new labelling regulations came into effect in Canada, suggesting that the required disclosure of TFA content on packages and/or the allowance of trans fat claims have acted as incentives to manufacturers to voluntarily reduce TFA in their products. However, reductions in TFA appeared to be restricted to higher-priced margarines, thereby limiting the scope of incentives to one particular market segment: the less price-conscious consumers. Although a national task force in Canada recommended a mandatory limit on the trans fat content of all vegetable oils and soft margarines in $2006^{(22)}$, manufacturers' reductions to date have been voluntary. Recent monitoring of TFA in soft margarines indicates some progress has been achieved through these voluntary measures, but more improvements are necessary ${ }^{(32)}$. Our results suggest there may be limited potential to improve the trans fat content of low-cost products through a voluntary approach. Thus this strategy may have little benefit for lower-income groups, who are at higher risk of heart disease. Marketplace interventions designed by governments to tackle population health issues need to be carefully considered, given the fiercely competitive nature of the market. Insofar as such interventions impact higher-income groups more than lower ones, they may simply function to increase health disparities.

\section{Acknowledgements}

There are no conflicts of interest and no sources of funding. L.R. and V.T. conceived the idea for the paper. K.L. collected data, and both K.L. and V.T. conducted data analyses. All authors contributed to the final version of the manuscript.

\section{References}

1. Health Canada (2003) Nutrition Labelling Toolkit for Educators. http://www.hc-sc.gc.ca/hpfb-dgpsa/onpp-bppn/ labelling-etiquetage/toolkit_educators_e.html (accessed September 2007).

2. Australia New Zealand Food Authority (2001) Overview of Food Labelling. http://www.foodstandards.gov.au/thecode/ assistanceforindustry/userguides/overviewoffoodlabell1267.cfm (accessed September 2007).

3. Balasubramanian SK \& Cole C (2002) Consumers' search and use of nutrition information: the challenge and promise of the Nutrition Labelling and Education Act. J Marketing 66, 112-127.

4. Food Standards Agency (1999) Guidance Notes on Nutrition Labelling. http://www.food.gov.uk/foodlabelling/ (accessed September 2007).

5. Health and Consumer Protection Directorate-General (2006) Labelling: competitiveness, consumer information and better regulation for the EU. A DG SANCO Consultative Document. http://ec.europa.eu/food/food/labellingnutrition/ betterregulation/competitiveness_consumer_info.pdf (accessed September 2008).
6. World Health Organization (2004) Global Strategy on Diet, Physical Activity and Health. Geneva: WHO.

7. Derby B \& Levy A (2001) Do food labels work? Gauging the effectiveness of food labels pre- and post-NLEA. In Handbook of Marketing and Society, pp. 372-398 [PN Bloom and GT Gundlach, editors]. Thousand Oaks, CA: Sage Publications.

8. Cowburn G \& Stockley L (2004) Consumer understanding and use of nutrition labelling: a systematic review. Public Health Nutr 8, 21-28.

9. Levy AS \& Fein SB (1998) Consumers' ability to perform tasks using nutrition labels. J Nutr Educ 30, 210-217.

10. Roe B, Levy AS \& Derby BM (1999) The impact of health claims on consumer search and product evaluation outcomes: results from FDA experimental data. J Public Policy Marketing 18, 89-105.

11. Lang $\mathrm{T} \&$ \& Heasman $\mathrm{M}$ (editors) (2004) The consumer culture. In Food Wars: The Global Battle for Mouths, Minds and Markets, pp. 184-203. London: Earthscan.

12. Mathios A \& Ippolito P (1999) Health claims in food advertising and labelling: disseminating nutrition information to consumers. In America's Eating Habits: Changes and Consequences, pp. 189-212 [E Frazao, editor]. Washington, DC: Economic Research Service, US Department of Agriculture.

13. Moorman C (1998) Market-level effects of information: competitive responses and consumer dynamics. J Marketing Res 35, 82-98.

14. Frazao E \& Allshouse J (1996) Size and Growth of the Nutritionally Improved Foods Market. Report no. AIB-723. Washington, DC: Economic Research Service, US Department of Agriculture.

15. Giskes K, Van Lenthe F, Brug J, Mackenbach J \& Turrell G (2007) Socio-economic inequalities in food purchasing: the contribution of respondent-perceived and actual (objectively measured) price and availability of foods. Prev Med 45, 41-48.

16. Hu FB, Manson JE \& Willett WC (2001) Types of dietary fat and risk of coronary heart disease: a critical review. $J \mathrm{Am}$ Coll Nutr 20, 5-19.

17. Kromhout D, Menotti A, Bloemberg B et al. (1995) Dietary saturated and trans fatty acids and cholesterol and 25-year mortality from coronary heart disease: the Seven Countries Study. Prev Med 24, 308-315.

18. Oh K, Hu FB, Manson JE, Stampfer M \& Willett WC (2005) Dietary fat intake and risk of coronary heart disease among women: 20 years follow-up of the Nurses Health Study. Am J Epidemiol 161, 672-679.

19. Stender S \& Dyerberg J (2004) Influence of trans fatty acids on health. Ann Nutr Metab 48, 61-66.

20. Eckel R, Borra S, Lichtenstein A \& Yin-Piazza S; Trans Fat Conference Planning Group (2006) Understanding the complexity of trans fatty acid reduction in the American diet; American Heart Association Trans Fat Conference 2006: Report of the Trans Fat Conference Planning Group. Circulation 115, 2231-2246.

21. Food Standards Australia New Zealand (2006) Government supports initiatives to reduce trans fats in food. http:// www.foodstandards.gov.au/newsroom/mediareleases/ mediareleases2006/honchristopherpynemp3389.cfm (accessed June 2007).

22. Health Canada (2006) TRANSforming the Food Supply: Report of the Trans Fat Task Force. Ottawa: Health Canada.

23. Canadian Food Inspection Agency (2004) 2003 Guide to Food Labelling and Advertising. Section 7.16 Fat Claims. http://www.inspection.gc.ca/english/fssa/labeti/guide/toce. shtml (accessed June 2007).

24. Canadian Food Inspection Agency (2004) 2003 Guide to Food Labelling and Advertising. Section 5.4 Information in the Nutrition Facts Table. http://www.inspection.gc.ca/english/ fssa/labeti/guide/ch5e.shtml\#5.4 (accessed June 2007). 
25. US Food and Drug Administration (2007) Federal Register Final Rule: Trans Fatty Acids in Nutrition Labelling, Nutrient Content Claims, and Health Claims. Washington, DC: US Department of Health and Human Services.

26. Elias SL \& Innis SM (2002) Bakery foods are the major dietary source of trans-fatty acids among pregnant women with diets providing 30 percent energy from fat. J Am Diet Assoc 102, 46-51.

27. US Food and Drug Administration (2004) Revealing Trans Fats. www.fda.gov/fdac/features/2003/503_fats.html (accessed June 2007).

28. Ricciuto L, Ip H \& Tarasuk V (2005) The relationship between price, amounts of saturated and trans fats, and nutrient content claims on margarines and oils. Can J Diet Pract Res 66, 252-255.

29. Gale Research Inc. (2002) Market Share Reporter. Farmington Hills, MI: Gale Group.

30. Gale Research Inc. (2006) Market Share Reporter 2006. Farmington Hills, MI: Gale Group.

31. Canadian Grocer (2006) Who's who 2006. Toronto, ON: Rogers Media Inc.
32. Health Canada (2008) Trans Fat Monitoring Program: Second Set of Monitoring Data. http://www.hc-sc.gc.ca/ fn-an/nutrition/gras-trans-fats/tfa-age_sec-data_deux-donneng.php (accessed August 2008).

33. Canadian Food Inspection Agency (2004) 2003 Guide to Food Labelling and Advertising. Section 7.16 Fat Claims. http://www.inspection.gc.ca/english/fssa/labeti/guide/toce. shtml (accessed June 2007).

34. Wilkinson R (1996) Income distribution and health. Unhealthy Societies: The Afflictions of Inequality, pp. 72-109. London: Routledge.

35. Hitchman C, Christie I, Harrison M \& Lang T (2002) Inconvenience Food: The Struggle to Eat Well on a Low Income. London: DEMOS.

36. Travers K (1996) The social organization of nutritional inequities. Soc Sci Med 43, 543-553.

37. Turrell G \& Kavanagh A (2006) Socio-economic pathways to diet: modelling the association between socio-economic position and food purchasing behaviour. Public Health Nutr 9, 375-383.

38. Horton S \& Campbell C (1990) Do the poor pay more for food? Food Market Commentary 11, 33-39. 